\title{
Praktek Manajemen Pengetahuan serta Dampaknya terhadap Kinerja Organisasi pada Perguruan Tinggi Swasta (PTS) di Kota Jambi
}

\author{
Jonner Simarmata \\ Dosen Manajemen pada Fakultas Ekonomi Universitas Batanghari, Jambi \\ Correspondence email: jonnerunbari@gmail.com
}

\begin{abstract}
Organizational performance is an important issue for researchers and managers including managers in Higher Education Institutions (HEIs) for it can be the indicator of success. It also provides accurate information for startegic decision making. Many factors influence organizational performance. One of them is knowledge management (KM) practices. Theoretically and empirically, effective KM practices improve performance. Many researches have been conducted in regard of HEI performance. Unfortunately, in the context of private HEIs in the City of Jambi, the literature and empirical evidences are very rare. This current research aims to fill the gap. It also aims to examine its link with organizational performance. Data was collected through the distribution of questionnaire to randomly-selected lecturers and employees. Further, the data was analyzed with regression analysis by applying SPSS V.26. The result shows that knowledge dissemination and knowledge storage system partially and simultenously affect organizational performance. Interestingly, the constanta value in the regression model is negative. This implies that performance might be decreased if KM is not implemented. Then, it is suggested to private HEI operators especially those in the City of Jambi implement KM.
\end{abstract}

Keywords: knowledge management, organizational performance, private HEIs

\section{Pendahuluan}

Kinerja organisasi diartikan sebagai kombinasi efektivitas dan efisiensi organisasi. Efektivitas diartikan sebagai kemampuan mencapai tujuan organisasi sedangkan efisiensi dipahami sebagai rasio antara pencapaian tujuan dengan penggunaan segala resources untuk mencapai tujuan tersebut. Terdapat banyak faktor yang mempengaruhi kinerja organisasi. Salah satunya adalah kompetensi SDM yang dimiliki organsiasi tersebut (Daft, 2000). Di masa lampau organisasi menggunakan aset intenjibel sebagai ukuran keberhasilan, posisi pasar, dan daya saing. Namun, dewasa ini, terjadi perubahan yang signifikan. Organsiasi tidak lagi fokus pada aset tenjibel tetapi pada aset intenjibel (Al-Hawary \& Alwan, 2016). Salah satu aset intenjibel adalah kompetensi yang di dalamnya termasuk pengetahuan. Perguruan tinggi merupakan sebuah entitas yang berbasis pengetahuan. Core business perguruan tinggi adalah menghasilkan lulusan. Salah satu kriteria yang digunakan untuk mengukur kualitas lulusan perguruan tinggi adalah kompetensi yang dimiliki atau dikuasai oleh lulusan tersebut setelah mengalami proses perkuliahan selama periode tertentu.Kompetensi adalah aset intenjibel yang sangat berharga. Tugas dosen dalam perkuliahan adalah mentransfer knowledge kepada mahasiswa dalam rangka meningkatkan kompetensi mahasiswa.

Salah satu tantangan yang harus dihadapi perguruan tinggi saat ini adalah persaingan yang semakin ketat. Di satu pihak, setiap perguruan tinggi melakukan berbagai upaya untuk menarik minat calon mahasiswa. Di pihak lain, calon mahasiswa semakin selektif dalam memilih perguruan tinggi. Mutu perguruan tinggi termasuk mutu pelayanan akademik dan pelayanan administrasi menjadi pertimbangan utama (Simarmata, 2018). Tantangan lainnya adalah pesatnya perkembangan ilmu pengetahuan dan teknologi yang membuat perguruan tinggi harus melakukan transformasi (Al-Hawary \& Alwan, 2016). Pada hakekatnya terdapat dua jenis pelayanan di perguruan tinggi yakni pelayanan akademik dan pelayanan non-akademik. Pelayanan akademik dilakukan oleh dosen dalam proses perkuliahan sedangkan pelayanan administrasi dilakukan oleh staff adminsitrasi dalam pengurusan administrasi kemahasiswaan. Mutu kedua jenis pelayanan ini merupakan faktor penting dalam memberikan kepuasan kepada mahasiswa. Kepuasan mahasiswa merupakan salah satu kriteria yang ditetapkan calon mahssiswa untuk memilih perguruan tinggi (Amin, 2017). Tingkat kompetensi karyawan dalam suatu organsiasi tidak selalu sama. Ada kelompok yang lebih unggul dibandingkan dengan kelompok lain. Untuk memastikan bahwa human capital yang ada dalam organsiasi memiliki kompetensi yang dibutuhkan melaksanakan tugas-tugasnya, organsiasi perlu mengimplementasikan manajemen pengetahuan. Fungsi manajemen pengetahuan adalah memastikan pengetahuan tersimpan, termanfaatkan, dan terdistribusikan secara efektif di dalam organisasi (Budihardjo, 2017).

Perguruan tinggi termasuk Perguruan Tinggi Swasta (PTS) berperan penting dan strategis dalam pembangunan bangsa terutama pengembangan sumberdaya manusia (SDM). Perguruan tinggi yang berkualitas mampu membangun SDM yang berkualitas pula, yang pada akhirnya membangun daya saing bangsa (Amin, 2017). Untuk mengembangkan PTS yang berkualitas perlu diimplementasikan manajemen pengetahuan yang efektif. Bila manajemen pengetahuan berjalan secara efektif maka kinerja PTS akan meningkat. Hal ini sejalan dengan RBT (Resource Based Theory) (J. 
Barney, 1991) dan KBT (Knowledge-Based Theory) (Grant, 1996) yang mengatakan bahwa human capital, bila dikelola dengan baik, merupakan sumberdaya yang sangat berharga, unik, dan langka dalam menciptakan daya saing. Implementasi manajemen pengetahuan mampu mengakumulasi human capital yang berdaya saing (Becker, 1993).

Di Kota Jambi, PTS mengalami pertumbuhan yang signifikan secara kuantitatif. Berdasarkan data dari Forlap Dikti, pada tahun 2019, di Kota Jambi terdapat 21 PTS dengan dosen sebanyak 829 orang, dan mahasiswa aktif sebanyak 18.317 orang. Meningkatnya jumlah PTS ini membawa konsekwensi yakni semakin ketatnya persaingan dalam merekrut calon mahasiswa. Salah satu strategi yang digunakan untuk memenangkan persaingan tersebut adalah meningkatkan pelayanan akademik dan pelayanan administrasi. Fakta ini juga menyarankan agar perguruan tinggi melakukan manajemen pengetahuan karena mutu pelayanan saat ini sangat tergantung kepada informasi yang dibutuhkan. Penelitian tentang manajemen pengetahuan pada konteks perguruan tinggi telah banyak dilakukan. Misalnya (Zwain, Teong, \& Othman, 2012). Namun, pada konteks PTS di Kota Jambi, kajian literatur dan bukti empiris tentang praktek manajemen masih jarang ditemukan. Padahal, PTS di Kota Jambi mengalami pertumbuhan yang signifikan. Artikel ini bertujuan untuk mengkaji praktek manajemen pengetahuan di PTS yang ada di Kota Jambi dan menguji hubungan variabel ini dengan kinerja organisasi. Diharapkan hasil penelitian ini akan menambah referensi pada kajian literatur dan masukan bagi pengelola PTS khususnya di Kota Jambi dalam rangka meningkatkan kualitas SDM dan kinerja organsiasinya.

\section{Landasan Teoritis \\ Konsep Pengetahuan}

Terdapat tiga istilah yang sering dipertukarkan penggunaannya walaupun sebenarnya mengandung arti yang berbeda. Istilah yang pertama adalah data yang diartikan sebagai angka dan fakta. Istilah yang kedua adalah informasi yang diartikan sebagai data yang sudah diolah. Dan istilah yang ketiga adalah pengetahuan yang diartikan sebagai informasi yang sudah memiliki otentitas (Dretske, 1981). Hingga kini, definisi pengetahuan masih bervariasi. Sebabnya, pengetahuan dapat dipandang dari berbagai perspektif, yakni: (1) dari perspektif 'state of mind, (2) sebagai objek, (3) sebagai sebuah proses, (4) sebagai sebuah akses, dan (5) sebagai kapabilitas (Alavi \& Leidner, 2001). Sebagai state of mind, pengetahuan dapat diartikan sebagai yang memungkinkan individu mengembangkan dan mengaplikasikan pengetahuan personalnya (Carlsson, Elsaway, Eriksson, \& Raven, 1996). Sebagai sebuah objek, pengetahuan diartikan sebagai sesuatu yang memungkinkan untuk dapat disimpan dan dimanipulasikan (Carlsson et al., 1996). Sebagai sebuah proses, pengetahuan memungkinkan seseorang untuk dapat mengaplikasikan keahliannya (Zack, 1998). Sebagai akses, pengetahuan memungkinkan seseorang untuk mengakses suatu konten dari sumbernya (McQueen, 1998). Terakhir sebagai kapabilitas, pengetahuan adalah sebuah potensi yang dapat mempengaruhi tindakan di masa yang akan datang (Carlsson et al., 1996). Perbedaan-perbedaan pandangan ini telah menyebabkan perbedaan dalam konsep manajemen pengetahuan(Carlsson et al., 1996).

\section{Konsep Manajemen Pengetahuan}

Bila pengetahuan dianggap sebagai sebuah objek atau akses, maka manajemen pengetahuan harus berfokus pada bagaimana mengembangkan dan mengelola 'stock' pengetahuan yang berupa alur atau proses pemerolehan (baca: creation), sharing, dan pendistribusian pengetahuan. Bila pengetahuan adalah kapabilitas maka manajemen pengetahuan adalah kegiatan yang berkaitan dengan pengembangan 'core competence', pemahaman keterampilan teknis yang stratejik, dan pemerolehan 'intellectual capital' (Carlsson et al., 1996).

\section{Praktek Manajemen Pengetahuan}

Praktek manajemen pengetahuan merupakan hasil aplikasi pengetahuan yang memungkinkan organsiasi beraktivitas secara unik (Alavi \& Leidner, 2001). Praktek manajemen pengetahuan berkaitan dengan isu-isu organisasi yang bersifat taktis dan operasional (Tallman, Jenkins, Henry, \& Pinch, 2004). Dalam literatur terdapat dua aktivitas utama manajemen pengetahuan yakni diseminasi pengetahuan (knowledge dissemination) dan sistem penyimpanan pengetahuan (knowledge storage system) (Alegre \& Chiva, 2012). Pembagian ini sesuai dengan pendekatan pengetahuan sebagai objek dan akses.

a. Knowledge Dissemination. praktek diseminasi pengatahuan adalah aktivitas yang berkaitan dengan penyebarluasan pengetahuan baik pengetahuan eksplisit maupun tacit ke seluruh organisasi melalui saluran formal atau informal. Tujuannya adalah memperlancar aplikasi pengetahuan oleh setiap individu dalam organisasi (Zahra \& George, 2002). Pada hakekatnya, diseminasi pengetahuan bukanlah hal yang mudah. Dibutuhkan pengelolaan yang efektif agar pengetahuan dapat tersebar secara efektif pula. Terutama diseminasi pengetahuan tacit perlu ditangani secara hati-hati. Kegiatan ini merupakan kegiatan tersulit dari seluruh kegiatan manajemen pengetahuan yang ada (Nonaka, 1994). Diperlukan interaksi antar individu yang cukup intensif. Hanya dengan interaksi semacam inilah 
Jonner Simarmata, Praktek Manajemen Pengetahuan serta Dampaknya terhadap Kinerja Organisasi pada Perguruan Tinggi Swasta (PTS) di Kota Jambi

pengetahuan tacit dapat tersebar. Sebabnya, pengetahuan tacit itu sendiri adalah pengetahuan yang sangat melekat pada diri individu. Dan pengetahuan tacit tersebut bersifat personal.

b. Knowledge Storage System. knowledge storage system berkaitan dengan prosedur penyimpanan dan penarikan pengetahuan secara sistematis. Sistem ini termasuk penggunaan information technology (IT) yang dikembangkan untuk menunjang proses bisnis sehari-hari (Alavi \& Leidner, 2001). Dengan adanya model penyimpanan pengetahuan secara sistematis memungkinkan organsiasi memiliki memori organisasional yang baik (Chang \& Cho, 2008). Memori organisasional maksudnya adalah terakumulasinya informasi sepanjang waktu sehingga dapat digunakan bilamana diperlukan.

\section{Kinerja Organisasi}

Kinerja Organisasi merupakan aspek penting dalam praktek bisnis. Terdapat dua alasan utama. Pertama, kinerja organisasi dapat dijadikan sebagai indikator tingkat keberhasilan organsiasi mencapai tujuan. Kedua, kinerja organisasi memberi infarmasi yang akurat tentang organisasi kepada manajemer dalam pengambilan keputusan stratejik (Daft, 2000).

a. Konsep Kinerja Organsiasi. kinerja organisasi diartikan sebagai kombinasi efektivitas dan efisiensi organsiasi. Efektivitas adalah kemampuan organsiasi encapai tujuan sedangkan efisiensi diartikan sebagai rasio pencapaian tujuan dengan penggunaan sumberdaya dalam encapai tujuan tersebut (Daft, 2000).

b. Pengukuran Kinerja Organsiasi, pengukuran kinerja organisasi publik seperti perguruan tinggi telah mendapat perhatian yang luas di kalangan akademisi. Misalnya (Usoh, 2017), (Abdullah, 2006) dan (Al-Hosaini \& Sofian, 2015). Secara tradisional, kinerja organisasi diukur dari aspek finansial. Hal ini disebabkan, pada umumnya, tujuan organsiasi adalah untuk mencapai laba setinggi-tingginya. Akan tetapi, ukuran tunggal ini tidak memadai lagi karena tidak dapat mencerminkan keberhasilan organsiasi secara keseluruahn. Oleh sebab itu diusulkan agar pengukuran kinerja organisasi mencakup tidak hanya aspek finansial tetapi juga aspek non-finansial. Dengan kata lain, harus ada perimbangan (Kaplan \& Norton, 1992)

Model pengukuran kinerja organisasi yang banyak digunakan adalah Balanced Scorecard atau yang sering disingkat dengan BSC. BSC adalah pengukuran kinerja organisasi yang komprehensif karena mencakup aspek finansial dan non-finansial. Berdasarkan BSC, kinerja organisai diukur dari empat perspektif yakni (1) perspektif keuangan, (2) perspektif pelanggan, (3) perspektif proses internal, dan (4) perspektif pembelajaran dan pertumbuhan (Kaplan \& Norton, 1992). Penggunaan BSC juga telah dilakukan di perguruan tinggi. Terdapat sejumlah literatur yang membahas penggunaan BSC dalam konteks perguruan tinggi. Misalnya (Al-Hawary \& Alwan, 2016), (Al-Hosaini \& Sofian, 2015) dan (Hladchenko, 2015).

\section{Hubungan Praktek Manajemen Pengetahuan dengan Kinerja Organisasi}

Para peneliti mengungkapkan bahwa praktek manajemen pengetahuan berpengaruh signifikan terhadap kinerja organsiasi. Bila manajemen pengetahuan diterapkan secara efektif maka akan dapat meningkatkan kinerja organisasi. Hal ini sejalan dengan teori RBT dan KBT yang mengatakan bahwa human capital yang mencakup knowledge, skill, capability, bila dikelaola dengan baik akan menjadi sumber penting bagi peningkatan kinerja dan daya saing organsiasi (J. B. Barney \& Arikan, 2008) (Grant, 1991).

\section{Model Penelitian dan Hipotesis}

Model penelitian ini memperlihatkan dua buah elemen manajemen pengetahaun yakni knowledge dissemination dan knolwledge storage system (Alegre, Sengupta, \& Lapiedra, 2013). Kedua elemen ini dalam penelitian ini diperlakukan sebagai variabel independen yang masing-masing berdiri sendiri. Berdasarkan model penelitian ini dapat diajukan hipotesis sebagai berikut:

H1. terdapat pengaruh signifikan knowledge dissemination (X1) terhadap kinerja organisasi (Y)

$\mathrm{H} 2$. terdapat pengaruh signifikan knowledge storage system (X2) terhadap kinerja organisasi (Y).

H3. terdapat pengaruh signifikan knowledge dissemination (X1) dan knowledge storage system (X2) secara simultan terhadap kinerja organisasi (Y).

Gambar 1

Model Penelitian

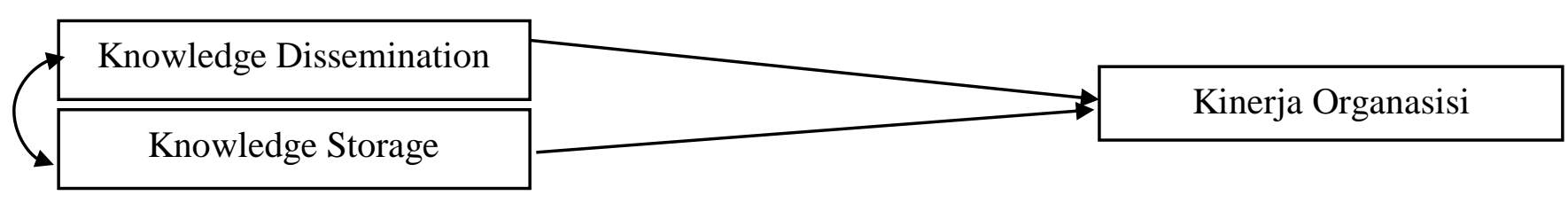




\section{Metode}

Penelitian ini adalah penelitian survey (Sugiyono, 2016). Dengan demikian, data dikumpulkan melalui penyebaran angket kepada responden yakni dosen dan karyawan PTS yang ada di Kota Jambi. Angket dalam penelitian ini adalah hasil adaptasi dari beberpa literatur yang menjadi referensi dalam penelitian ini. Angket disebarkan dengan cara mendatangi responden secara langsung. Responden diberi waktu selama satu sampai dengan tiga minggu untuk mengisi angket. Kemudian, angket dikumpulkan dengan kembali mendatangi responden. Dalam penelitian ini, pengukuran data dilakukan dengan Skala Likert 7-poin dengan rentang penilaian mulai dari 1 yang berarti sangat tidak setuju hingga 7 yang berarti sangat setuju. Skala Likert 7-poin merupakan pengembangan skala 5-poin. Belakangan ini, penggunaan skala 7-poin semakin populer di kalangan peneliti terutama peneliti manajemen dan ilmu sosial lainnya. Penyebabnya adalah skala 7-poin lebih mampu mengeksplor persepsi responden secara lebih rinci. Berdasarkan data dari Forlap Dikti, saat ini terdapat sebanyak 829 orang dosen PTS yang tersebar diberbagai PTS yang ada di Kota Jambi. Jumlah sampel ditetapkan sebesar 25\% yang ditarik secara random dari empat PTS yang dianggap memadai dari segi jumlah dosen. Diketahui bahwa empat perguruan tinggi dimaksud secara kumulatif memiliki sebanyak 341 orang dosen. Dengan demikian terdapat 87 orang yang menjadi sampel dalam penelitian ini. Instrumen penelitian harus reliabel dan valid. Instrumen yang reliabel adalah instrumen yang dapat diandalkan dalam melakukan pengukuran. Artinya, instrumen tersebut memberikan hasil yang konsisten. Dengan demikian, tidak ada keraguan untuk menggunakan instrumen tersebut (Sugiyono, 2016). Untuk mengukur reliabilitas instrumen digunakan Chronbah's Alpha Coefficient. Kriteria pengukurannya adalah bila nilai koefisien alpha sama dengan atau lebih besar daripada 0.60 maka instrument dinilai reliabel. Tabel 2 memperlihatkan bahwa nilai koefisien alfa untuk semua variabel berada di atas 0,60. Oleh sebab itu, instrumen yang digunakan dalam penelitian ini harus dianggap reliabel atau layak digunakan.

Tabel 1

Hasil Uji Validitas dan Uji Reliabilitas Instrumen

\begin{tabular}{|c|c|c|c|}
\hline Variabel & Item & Pearson Correlation Coefficient & Chronbah's Alpha Coefficient \\
\hline \multirow{6}{*}{$\begin{array}{l}\text { Knowledge } \\
\text { Dissemination }\end{array}$} & 1. Sistem kodifikasi & 0,763 & \multirow{6}{*}{ 然 } \\
\hline & 2. Foral sharing & 0,501 & \\
\hline & 3. Informal sharing & 0,912 & \\
\hline & 4. Sistem distribusi & 0,916 & \\
\hline & 5. Dukungan fasilitas & 0,710 & \\
\hline & 6. Partisipasi anggota & 0,818 & \\
\hline \multirow{6}{*}{$\begin{array}{l}\text { Knowledge } \\
\text { Storage } \\
\text { system }\end{array}$} & 1. Sistem pengupulan & 0,439 & \\
\hline & 2. Sistem processing & 0,876 & \multirow{5}{*}{0,791} \\
\hline & 3. Sistem pengawasan & 0,810 & \\
\hline & 4. Sistem updating & 0,452 & \\
\hline & 5. Sistem akses & 0,803 & \\
\hline & 6. Sistem pemberian feedback & 0,714 & \\
\hline \multirow{6}{*}{$\begin{array}{l}\text { Kinerja } \\
\text { Organi sasi }\end{array}$} & 1. Kepuasan mahasiswa & 0,760 & \multirow{6}{*}{0,727} \\
\hline & 2. Kepuasan dosen dan karyawan & 0,806 & \\
\hline & 3. Peningkatan jumlah mahasiswa & 0,303 & \\
\hline & 4. Peningkatan penghasilan dosen dan karyawan & 0,788 & \\
\hline & 5. Peningkatan mutu lulusan & 0,556 & \\
\hline & 6. Reputasi PTS & 0,816 & \\
\hline
\end{tabular}

Sumber: data olahan

Validitas merujuk pada kemampuan instrumen untuk mengukur apa yang harus diukur (Sugiyono, 2016). Koefisien korelasi dari Pearson digunakan untuk mengukur validitas. Kriteria yang digunakan adalah apabila nilai thitung lebih besar daripada nilai t-tabel maka instrumen dinilai valid. Tabel 1 memperlihatkan bahwa semua koefisien korelasi berada di atas nilai t-tabel $(0,213)$. Dengan demikian, semua item pertanyaan dalam instrumen adalah valid.

\section{Hasil \\ Analisis Statistik Deskriptif}

Tabel 2 memperlihatkan bahwa rata-rata responden memberi skor pada setiap item pernyataan adalah pada level tinggi. Hanya beberapa yang berada pada level sangat tinggi. Kemudian tidak ada pada level rendah atau sangat rendah. Dengan demikian dapat disimpulkan bahwa praktek manajemen pengetahuan pada PTS di Kota Jambi telah berlangsung dengan baik. Demikian pula dengan kinerja organisasi juga berada pada level yang baik. Sepintas dapat diduga bahwa praktek manajemen pengetahuan ini berpengaruh terhadap kinerja organsiasi. Oleh sebab itu perlu dilakukan uji hipotesis. 
Jonner Simarmata, Praktek Manajemen Pengetahuan serta Dampaknya terhadap Kinerja Organisasi pada Perguruan Tinggi Swasta (PTS) di Kota Jambi

Tabel 2

Deskripsi Data Variabel Knowledge Dissemination

\begin{tabular}{llcl}
\hline \multicolumn{1}{c}{ Item Pernyataan } & Score & $\%$ & Level \\
\hline 1. Sistem kodifikasi & 512 & 84 & Sangat Tinggi \\
2. Foral sharing & 456 & 75 & Tinggi \\
3. Informal sharing & 480 & 79 & Tinggi \\
4. Sistem distribusi & 503 & 83 & Sangat Tinggi \\
5. Dukungan fasilitas & 430 & 71 Tinggi \\
6. Partisipasi anggota & 439 & 72 Tinggi \\
Total & 2820 & 77 Tinggi \\
\hline
\end{tabular}

Sumber: data olahan

Tabel 3

Deskripsi Data Variabel Knowledge Storage System

\begin{tabular}{llll}
\hline \multicolumn{1}{c}{ Item Pernyataan } & Score & $\%$ & \multicolumn{2}{c}{ Level } \\
\hline 1. Sistem pengupulan & 471 & 77 & Tinggi \\
2. Sistem processing & 454 & 75 & Tinggi \\
3. Sistem pengawasan & 418 & 69 & Tinggi \\
4. Sistem updating & 482 & 79 & Tinggi \\
5. Sistem akses & 496 & 81 Sangat Tinggi \\
6. Sistem pemberian feedback & 474 & 78 Tinggi \\
Total & 2795 & 77 Tinggi \\
\hline
\end{tabular}

Sumber: data olahan

Tabel 4

Deskripsi Data Variabel Kinerja Organsiasi

\begin{tabular}{llrll}
\hline \multicolumn{1}{c}{ Item Pernyataan } & Score & \% & Level \\
\hline 1. Kepuasan mahasiswa & 429 & 70 & Tinggi \\
2. Kepuasan dosen dan karyawan & 498 & 82 & Sangat Tinggi \\
3. Peningkatan jumlah mahasiswa & 460 & 76 & Tinggi \\
4. Peningkatan penghasilan dosen dan karyawan & 462 & 76 & Tinggi \\
5. Peningkatan mutu lulusan & 494 & 81 & Sangat Tinggi \\
6. Reputasi PTS & 441 & 72 & Tinggi \\
Total & 2795 & 76 & Tinggi \\
\hline
\end{tabular}

Sumber: data olahan

Tabel 5

Koefisien Korelasi dan Diterminansi

\begin{tabular}{llrrrr}
\hline & Model & R & R Square & Adjusted R Square & Std. Error of the Estimate \\
\hline 1 & $.855^{\mathrm{a}}$ & .731 & & .725 & \\
\hline
\end{tabular}

Sumber: data olahan

Tabel 5 terlihat bahwa nilai koefisein korelasi adalah .855. Ini berarti variabel independen dan variabel dependen memiliki hubungan yang sangat kuat. Sementara itu, nilai koefisien diterminansi (R) adalah .731 yang berarti 73,1\% variansi yang ada pada variabel dependen dapat dijelaskan oleh variabel independen. Sedangkan sisanya sebesar $26,9 \%$ dijelaskan oleh variabel lain yang tidak diteliti dalam penelitian ini. Model regresi yang digunakan dalam penelitian ini adalah Model Regresi Linear Berganda karena terdapat dua variabel berpengaruh yakni knowledge dissemination (X1) dan knowledge storage system (X2). Analisi ini bertujuan untuk mengetahui seberapa jauh pengaruh X1 dan X2 terhadap Y baik secara parsial maupun secara simultan. Hasil analisis regresi dapat dilihat pada Tabel 4.

Tabel 6

Hasil Analisis Regresi

\begin{tabular}{|c|c|c|c|c|}
\hline \multicolumn{2}{|c|}{ Unstandardized Coefficients } & \multicolumn{3}{|l|}{ Standardized Coefficients } \\
\hline B & Std. Error & Beta & $\mathrm{t}$ & Sig. \\
\hline-2.932 & 2.375 & & -1.235 & .220 \\
\hline .776 & .100 & .653 & 7.773 & .000 \\
\hline .305 & .102 & .250 & 2.976 & .004 \\
\hline
\end{tabular}

Sumber: data olahan

Berdasarkan tabel ini maka dapat disusun model regresi berganda sebagai berikut: 
Jonner Simarmata, Praktek Manajemen Pengetahuan serta Dampaknya terhadap Kinerja Organisasi pada Perguruan Tinggi

$Y=(2,932)+0,776 X 1+0,305 X 2$

Persamaan ini dapat dijelaskan sebagai berikut:

(a). Nilai konstanta adalah $(2,932)$ yang berarti kinerja organisasi pada PTS di Kota Jambi mengalami nilai negatif sebesar 2,932 bila tidak melakukan praktek manajemen pengetahuan secara efektif.

(b). Nilai koefisien regresi variabel X1 adalah 0,776 yang berarti praktek disseminasi pengetahuan (X1) memberi kontribusi sebesar 0,776 bila kinerja organisasi pada PTS di Kota Jambi meningkat sebesar satu unit.

(c). Nilai koefisien regresi variabel X2 adalah 0,305 yang berarti praktek penyimpanan pengetahuan (X2) memberi kontribusi sebesar 0,305 bila kinerja organisasi pada PTS di Kota Jambi meningkat sebesar satu unit.

(d). Nilai koefisien regresi variabel X1 yakni diseminasi pengetahuan lebih besar dibandingkan dengan nilai koefisien variabel X2 yakni penyimpanan pengetahuan. Ini mengindikasikan bahwab berbagi pengetahuan jauh lebih penting dibandingkan dengan penyimpanan pengetahuan. Ini berarti pula, menyebarkan informasi jauh lebih bermanfaat daripada hanya disimpan tetapi tidak digunakan.

Uji t digunakan untuk membuktikan $\mathrm{H} 1$ dan $\mathrm{H} 2$. Kriteria pengujian yang digunakan adalah sebagai berikut:

(a). Jika nilai sig < 0,05 maka Ha diterima atau disimpulkan variabel X1 berpengaruh signifikan terhadap variabel Y.

(b). Jika nilai sig > 0,05 maka Ha ditolak atau disimpulkan variabel X1 tidak berpengaruh signifikan terhadap variabel Y.

Pada tabel 3 terlihat bahwa nilai signifikansi variabe X1 adalah 0,000 lebih kecil daripada 0,005, maka disimpulkan bahwa knowledge dissemination X1 berpengaruh signifikan terhadap kinerja organsiasi $\mathrm{Y}$, juga terlihat bahwa nilai signifikansi variabel X2 adalah 0,004 lebih kecil daripada 0,005, maka dapat disimpulkan bahwa knowledge storage system $\mathrm{X} 2$ berpengaruh signifikan terhadap kinerja organisasi $\mathrm{Y}$.

Uji F digunakan untuk membuktikan $\mathrm{H} 3$. Kriteria pengujian yang digunakan adalah sebagai berikut:

(a). Jika nilai sig < 0,05 maka Ha diterima atau disimpulkan bahwa variabel X1 berpengaruh signifikan terhadap variabel Y.

(b). Jika nilai sig > 0,05 maka Ha ditolak atau disimpulkan variabel X1 tidak berpengaruh signifikan terhadap variabel (Y).

Tabel 7

Hasil Uji F

\begin{tabular}{llrrrrr}
\hline & Model & Sum of Squares & df & Mean Square & F & Sig. \\
\hline 1 & Regression & 1952.586 & 2 & 976.293 & 114.311 & $.000^{\mathrm{b}}$ \\
& Residual & 717.414 & 84 & 8.541 & & \\
& Total & 2670.000 & 86 & & & \\
\hline
\end{tabular}

Sumber: data olahan

Tabel 7 terlihat bahwa nilai signifikansi adalah 0,000 lebih kecil daripada 0,005. Dengan demikian H3 dapat diterima. Dengan kata lain variabel X1 dan X2 secara simultan berpengaruh signifikan terhadap variabel Y. Berdasarkan hasil pengolahan data di atas dapat diberikan beberapa interpretasi sebagai berikut:

(a). Terbukti bahwa variabe X1 yakni knowledge dissemination berpengaruh signfikan terhadap kinerja organsiasi (Y) pada PTS di Kota Jambi.

(b). Terbukti bahwa variabel X2 yakni knowledge storage system berpengaruh signifikan terhadap kinerja organisasi (Y) pada PTS di Kota Jambi.

(c). Terbukti bahwa variabe X1 yakni knowledge dissemination dan variabel $\mathrm{X} 2$ yakni knowledge storage system secara simultan berpengaruh signifikan terhadap kinerja organisasi (Y) pada PTS di Kota Jambi.

(d). Koefisien regresi variabe X1 lebih besar daripada koefisien regresi X2. Ini menunjukkan bahwa peran praktek penyebaran informasi dalam membentuk kinerja organisasi lebih besar daripada peran praktek penyimpanan pengetahuan.

(e). Peran manajemen pengatahuan secara keseluruhan sangat besar terhadap kinerja organsiasi. Hal ini terbukti dari nilai konstanta yang negatif, yang berarti nilai kinerja organsiasi pada PTS di Kota Jambi bisa negatif atau berkurang bila manajemen pengetahuan tidak diimplementasikan.

\section{Pembahasan}

Teori Human Capital (Becker, 1993), RBT ((J. Barney, 1991), dan KBT (Grant, 199) mengemukakan bahwa SDM merupakan sumberdaya yang sangat penting bagi organsiasi. SDM merupakan sumberdaya yang berharga, unik, langka, dan non-subtitusional dapat menghasilkan keberhasilan bagi organisasi dan kemudian menciptakan keunggulan bersaing. Namun, perlu diingat bahwa agar SDM dapat berkontribusi dengan baik maka perlu ada pengelolaan yang efektif. Dewasa ini, keberhasilan organsiasi sangat tergantung pada penguasaan informasi. Oleh sebab itu manajemen pengetahuan merupakan syarat mutlak untuk meningkatkan efektivitas organisasi. Terutama dalam konteks perguruan 
Jonner Simarmata, Praktek Manajemen Pengetahuan serta Dampaknya terhadap Kinerja Organisasi pada Perguruan Tinggi Swasta (PTS) di Kota Jambi

tinggi termasuk PTS sebagai entitas yang berbasis pengetahuan manajemen pengetahuan terasa semakin penting. Hal ini terbukti dari temuan penelitian ini yang mengungkakan bahwa nilai konstanta dalam model regresi adalah negatif. Ini menunjukkan bahwa manajemen pengetahuan bila tidak diimplementasikan maka kinerja PTS terutama PTS yang berada di Kota Jambi akan menurun. Ini berarti pula bahwa bila manajemen pengetahuan diterapkan dengan baik maka akan dapat meningkatkan kinerja PTS.

\section{Simpulan}

Berdasarkan hasil penelitian dapat disimpulkan sebagai berikut:

1. Terbukti bahwa variabe $\mathrm{X}_{1}$ yakni knowledge dissemination berpengaruh signfikan terhadap kinerja organsiasi (Y) pada PTS di Kota Jambi.

2. Terbukti bahwa variabel $\mathrm{X}_{2}$ yakni knowledge storage system berpengaruh signifikan terhadap kinerja organisasi (Y) pada PTS di Kota Jambi.

3. Terbukti bahwa variabe $\mathrm{X}_{1}$ yakni knowledge dissemination dan variabel $\mathrm{X}_{2}$ yakni knowledge storage system secara simultan berpengaruh signifikan terhadap kinerja organisasi (Y) pada PTS di Kota Jambi.

4. Koefisien regresi variabe $X_{1}$ lebih besar daripada koefisien regresi $X_{2}$. Ini menunjukkan bahwa peran praktek penyebaran informasi dalam membentuk kinerja organisasi lebih besar daripada peran praktek penyimpanan pengetahuan.

5. Peran manajemen pengatahuan secara keseluruhan sangat besar terhadap kinerja organsiasi. Hal ini terbukti dari nilai konstanta yang negatif, yang berarti nilai kinerja organsiasi pada PTS di Kota Jambi bisa negatif atau berkurang bila manajemen pengetahuan tidak diimplementasikan.

\section{Daftar Pustaka}

Abdullah, F. (2006). Measuring service quality in higher education: HEdPERF versus SERVPERF. Marketing Intelligence and Planning, 24(1), 31-47. https://doi.org/10.1108/02634500610641543

Al-Hawary, S. I. S., \& Alwan, A. M. (2016). Knowledge Management and Its Effect on Strategic Decisions of Jordanian Public Universities. Journal of Accounting, Business \& Management, 23(2), 21-41. Diambil dari http://escweb.lib.cbs.dk/login?url=http://search.ebscohost.com/login.aspx?direct=true\&db=bth\&AN=125029888\&site= ehost-live

Al-Hosaini, F. F., \& Sofian, S. (2015). A Review of Balanced Scorecard Framework in Higher Education Institution (HEIs). International Review of Management and Marketing, 5(1), 26-35. Diambil dari www.econjournals.com

Alavi, M., \& Leidner, D. E. (2001). Review: Knowledge Management and Knowledge Management systems: conceptual foundations and research issues. Knowledge Management and Knowledge Management Systems: Conceptual Foundations and Research Issues, 25(1), 107-136. https://doi.org/10.2307/3250961

Alegre, J., \& Chiva, R. (2012). Assessing the impact of organizational learning capability on product innovation performance: An empirical test. African Journal of Business Management, 6(12), 3522-4535. https://doi.org/10.5897/AJBM11.2463

Alegre, J., Sengupta, K., \& Lapiedra, R. (2013). Knowledge management and innovation performance in a high-tech SMEs industry. International Small Business Journal, 31(4), 454-470. https://doi.org/10.1177/0266242611417472

Amin, S. (2017). Strategi Peningkatan Kualitas Pelayanan Akademik pada Perguruan Tinggi. Jurnal Madaniyah, 7(2), $222-236$.

Barney, J. (1991). Firm Resources and Sustained Competitive Advantage. Journal of Management, 17(1), 99-120. https://doi.org/10.1177/014920639101700108

Barney, J. B., \& Arikan, A. M. (2008). The Resource-based View: Origins and Implications. The Blackwell Handbook of Strategic Management, 123-182. https://doi.org/10.1111/b.9780631218616.2006.00006.x

Becker, G. S. (1993). Human Capital: a theoritical and empirical analysis with special reference to education (Third Edit). https://doi.org/10.4324/9781315145136-9

Budihardjo, A. (2017). Knowledge Management: Evektivitas berinovasi meraih sukses. Jakarta: Prasetya Mulya Publishing.

Carlsson, S. A., Elsaway, O. A., Eriksson, I., \& Raven, A. (1996). Gaining competitive advantage through shared knowledge creation: in search of a new design theory for strategic information systems. Proceedings of the Fourth European Conference on Information System, 1067-1075. Lisbon.

Chang, D. R., \& Cho, H. (2008). Organizational memory influences new product success. Journal of Business Research, 61(1), 13-23. https://doi.org/10.1016/j.jbusres.2006.05.005

Daft, R. L. (2000). Organization Theory and Design (7th ed.). USA: South-Western College Publishing. Thomson Learning. 
Jonner Simarmata, Praktek Manajemen Pengetahuan serta Dampaknya terhadap Kinerja Organisasi pada Perguruan Tinggi Swasta (PTS) di Kota Jambi

Dretske, F. (1981). Knowledge and the Flow of Information. Cambridge, UK: MIT Press Cambridge.

Grant, R. M. (1991). The Resource-Based Theory of Competitive Advantage: Implications for Strategy Formulation. California Management Review, 1991(Spring), 114-135.

Grant, R. M. (1996). Toward a Knowledge-Based Theory of the firm. Strategi Management Journal, 17(Special Issue), 109-122. Diambil dari http://memberfiles.freewebs.com/84/90/65819084/documents/TOWARD A KNOWLEDGE-BASED THEORY OF THE.pdf

Hladchenko, M. (2015). Balanced Scorecard - a strategic management system of the higher education institution. International Journal of Education Management, 29(2), 167-176. https://doi.org/10.1108/JJEM-11-2013-0164

Kaplan, R. S., \& Norton, D. P. (1992). The Balanced-Scorecard - Measures that Drive Performance. Harvard Business Review, 1, 71-79.

McQueen, R. (1998). Four Views of Knowledge and Knowledge Management. In E. Hoadley \& I. Benbasat (Ed.), Proceedings of the Fourth Americas Conference on Information Systems (hal. 609-611).

Nonaka, I. (1994). A Dynamic Theory of Organizational Knowledge Creation. Organizational Science, 5(1).

Simarmata, J. (2018). Praktek Manajemen Kerja dan Kinerja Organisasi pada Universitas batanghari: Peran Budaya Organisasi sebagai Variabel Moderator. J-MAS (Jurnal Manajemen dan Sains), 3(2), 137-145.

Sugiyono. (2016). Metode Penelitian Manajemen. Bandung: Penerbit Alfabeta.

Tallman, S., Jenkins, M., Henry, N., \& Pinch, S. (2004). Knowledge , Clusters , and Competitive Advantage University of Utah. Academy of Management Review, 29(2), 258-271.

Usoh, E. J. (2017). Strategic Planning and Performance Measurement for Public Universities in Sulawesi, Indonesia. PEOPLE: International Journal of Social Science, 3(3), 174-197.

Zack, M. (1998). An architecture for managing explicated knowledge. Sloan Management Review, 39(4), 45-58.

Zahra, S. A., \& George, G. (2002). Absorptive capacity: A review, reconceptualization, and extension. Academy of Management Review, 27(2), 185-203. https://doi.org/10.5465/AMR.2002.6587995

Zwain, A. A. A., Teong, L. K., \& Othman, S. N. (2012). Knowledge Management and Academic Performance: An Empirical Study of Iraqi HEIs. (July), 4-6. 